University of Nebraska - Lincoln

DigitalCommons@University of Nebraska - Lincoln

Publications, Agencies and Staff of the U.S.

Department of Commerce

U.S. Department of Commerce

2015

\title{
Evaluation of the 2012 Drought with a Newly Established National Soil Monitoring Network
}

\author{
Jesse E. Bell \\ North Carolina State University, jesse.bell@noaa.gov \\ Ronald D. Leeper \\ North Carolina State University \\ Michael A. Palecki \\ NOAA, National Centers for Environmental Information, Asheville NC \\ Evan Coopersmith \\ USDA-ARS, Hydrology and Remote Sensing Laboratory, Beltsville, MD \\ Tim Wilson \\ NOAA, Atmospheric Turbulence and Diffusion Division, Oak Ridge, TN
}

See next page for additional authors

Follow this and additional works at: https://digitalcommons.unl.edu/usdeptcommercepub

Bell, Jesse E.; Leeper, Ronald D.; Palecki, Michael A.; Coopersmith, Evan; Wilson, Tim; Bilotta, Rocky; and Embler, Scott, "Evaluation of the 2012 Drought with a Newly Established National Soil Monitoring Network" (2015). Publications, Agencies and Staff of the U.S. Department of Commerce. 528.

https://digitalcommons.unl.edu/usdeptcommercepub/528

This Article is brought to you for free and open access by the U.S. Department of Commerce at DigitalCommons@University of Nebraska - Lincoln. It has been accepted for inclusion in Publications, Agencies and Staff of the U.S. Department of Commerce by an authorized administrator of DigitalCommons@University of Nebraska - Lincoln. 


\section{Authors}

Jesse E. Bell, Ronald D. Leeper, Michael A. Palecki, Evan Coopersmith, Tim Wilson, Rocky Bilotta, and Scott Embler 


\section{Original Research}

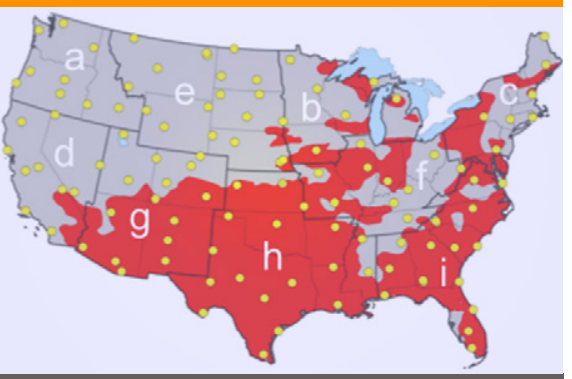

Core Ideas

- New US soil moisture network pro-

vides new opportunity to evaluate

drought

- Soil moisture at deeper depths

did not fully recover from the 2012

drought in 2013

- Soil moisture varied by region in the

response to drought

J.E. Bell and R.D. Leeper, Cooperotive Institute for Climate and Satellites North Carolina State Univ., 151 Patton Avenue, Asheville, NC 28801; J.E. Bell, R.D. Leeper, M. Palecki, R. Bilotta, and S. Embler, NOAA, National Centers for Environmental Information, 151 Patton Avenue, Asheville NC 28801; E. Coopersmith, USDA-ARS, Hydrology and Remote Sensing Laboratory, Beltsville, MD 20705; T. Wilson, NOAA, Atmospheric Turbulence and Diffusion Division, 456 S. Illinois Ave, Oak Ridge, TN 37830; and R. Bilotta and S. Embler, ERT, Inc., 151 Patton Ave, Asheville, NC 28801. *Corresponding author (jesse.bell@noaa.gov).

Vadose Zone J.

doi:10.2136/vzj2015.02.0023

Received 6 Feb. 2015

Accepted 6 Aug. 2015

This document is a U.S. government work and is not subject to copyright in the United States.

(c) Soil Science Society of America 5585 Guilford Rd., Madison, WI 53711 USA. All rights reserved.

\section{Evaluation of the 2012 Drought with a Newly Established National Soil Monitoring Network}

\author{
Jesse E. Bell,* Ronald D. Leeper, Michael A. Palecki, Evan \\ Coopersmith, Tim Wilson, Rocky Bilotta, and Scott Embler
}

The NOAA United States Climate Reference Network (USCRN) deployed soil moisture sensors during 2009 to 2011 to monitor the temporal and spatial variability of soil moisture at 114 locations in the contiguous United States. These new soil observations will enhance our understanding of changing soil conditions for better drought monitoring. One year after full deployment of the network, a large drought occurred across most of the United States and provided an opportunity to evaluate the utility of this network for drought monitoring. The soil moisture signal of the 2012 drought in the continental United States was detected nationally at all observational depths $(5,10,20$, 50 , and $100 \mathrm{~cm}$ ), with an overall $11.07 \%$ decrease from the average of the 2011 to 2013 summers. The top three depths $(5,10$, and $20 \mathrm{~cm})$ experienced the largest decrease in soil moisture. Although 2013 national precipitation totals returned to normal values and national soil moisture levels recovered from the 2012 drought, the national average soil moisture concentrations combined at the 50 - and $100-\mathrm{cm}$ depths remained around $18 \%$ below predrought levels. Regional analysis of the 2012 drought identified that the Upper Midwest, Northeast, Northern Rockies and Plains, and Ohio Valley climate regions were most impacted and demonstrated a temporal pattern similar to the national analysis. These results demonstrate the utility of using USCRN for monitoring national soil moisture conditions, assessing droughts, and tracking climate change with time.

Abbreviations: JJA, June, July, and August; USCRN, United States Climate Reference Network.

The drought of 2012 in the center of the United States was historic in proportion and impact, following a very wet year that caused major flooding in the Missouri River basin and a historical drought in the Southern Plains (Fuchs et al., 2015). 2012 started with very little drought in the north-central United States but abnormally warm conditions that, during spring, led to rapid drying in areas receiving normal or less than normal rainfall. Every state from the East Coast to the Great Plains experienced its warmest or second warmest March through May on record. Both heat and very low precipitation brought drought to severe levels in June through August 2012, with seven states in the central United States ending one of the 10 driest summers in $118 \mathrm{yr}$ of climate records. Drought conditions continued into the fall, with more typical precipitation slowly returning to the region from east to west during late fall and winter.

The USCRN recently installed soil moisture and temperature instrumentation provides an opportunity to evaluate changes in soil climate across a national domain with uniform observations (Diamond et al., 2013; Bell et al., 2013). The main purpose for adding the soil moisture instrumentation was to improve drought-monitoring capabilities in the United States, as well as to provide soil moisture and temperature observations to assist with validation of climate models and remotely sensed measurements. Because drought frequency and intensity may increase in the future (Dai, 2013), there is an important need for the near-real-time drought monitoring capabilities that USCRN observations can provide (Hayes et al., 2011; Ochsner et al., 2013). Because the addition of soil observations 
to the network was only recently completed (August 2011), there has been limited opportunity to use these measurements for an evaluation of long-term changes in drought conditions or soil climate. However, a year after installation was completed, a drought of historical proportions spread across the United States during 2012 (Hoerling et al., 2013), providing an opportunity to test the capabilities of these new measurements. The associated changes in precipitation and drought severity from 2011 to 2013 (Blunden and Arndt, 2014) provide a unique opportunity to understand the corresponding changes in soil moisture conditions.

The drought of 2012 spanned $>80 \%$ of the United States at its peak, caused around US $\$ 30$ billion in damage, and contributed to an estimated 123 deaths, prompting federal relief efforts (Hoerling et al., 2013; Smith and Katz, 2013). This drought was considered one of the most severe and damaging droughts since the Dust Bowl of the 1930s (Basara et al., 2013). Although the drought of 2012 spread across most of the United States, the most intense and severe drought conditions occurred in the northern Great Plains and Midwest of the United States (Peterson et al., 2013; Hoerling et al., 2014). By understanding the regional changes in soil moisture conditions that occurred before, during, and after the drought of 2012, improvements in the determination of drought status are possible (Svoboda et al., 2002). While abnormally dry to exceptional drought conditions for most of the United States were reached in 2012, the US Drought Monitor indicated that this was preceded by an extreme drought in the Southern Plains and western Gulf regions in 2011 (NOAA, 2011), and drought continued in western regions in 2013 (Blunden and Ardnt, 2014). Newly established national networks that monitor soil moisture can provide unique observations of drought, but these observations must be analyzed in a way that accounts for spatial variability and short time spans.

The USCRN provides a variety of standard measurements at each station, including high-quality precipitation measurements (Diamond et al., 2013). Because precipitation is one common factor for indicating drought status (Guttman 1999), the changes in precipitation at each USCRN station also provide an ideal opportunity to evaluate their correspondence with changes in soil moisture (Palecki and Bell, 2013). The USCRN soil observations were compared with USCRN precipitation observations at both national and regional scales. These data were standardized to report the percentage of deviation from the mean to accurately compare values between regions. Modeled soil moisture for the period 2004 to 2010 provided additional years of analysis to determine the severity and magnitude of the change in soil moisture during the 2012 drought, as an extended record improves the historical context of the analysis. Although this analysis was performed retrospectively, a near-real-time examination could be performed to help guide planners and managers of water resources.

\section{Materials and Methods}

\section{USCRN Soil Observations}

The USCRN has 114 stations monitoring soil climate across the continental United States (Diamond et al., 2013). Locations of these stations were selected to examine the temperature and precipitation variations of the United States (Vose and Menne, 2004). The goals of the network are to provide a long-term climate record with homogenous instrumentation in stable settings that would also be useful for many applications and serve as a high-quality reference for other existing stations and networks. In 2009, the capabilities of the USCRN were augmented with the installation of soil probes that monitor temperature and moisture at each station (Bell et al., 2013). Completed in August 2011, stations that are able to support the full installation have three sets of probes at five depths $(5,10,20,50$, and $100 \mathrm{~cm})$. Stations with shallow soil conditions that do not allow full installation have only 5 - and $10-\mathrm{cm}$ probes installed, and this issue is especially prominent in the western regions. The redundancy of three sets of measurements at each site improves the quality and continuity of the record at each depth (Bell et al., 2013; Palecki and Bell, 2013).

The soil probe technology installed by the USCRN uses a reflected electromagnetic radio wave to determine the dielectric permittivity of the soil matrix and a thermistor to measure temperature. The device (Hydra Probe II Soil Moisture and Salinity Sensor, SDI-12 model, Stevens Water Monitoring Systems, Inc.) output is converted to volumetric water content using a general equation (Seyfried et al., 2005). Recorded values from the stations are transmitted to NOAA's National Centers for Environmental Information from the field sites via the Geostationary Operational Environmental Satellite data collection system. Upon ingest, there are a series of quality control checks to assure data quality. Hourly averages of the soil moisture values from the three individual probes are then calculated at each depth. On a monthly basis, the values are post-processed with a series of statistical tests to identify any defective probes or measurements that were not detected with the initial quality control. The soil moisture values were used directly as volumetric water content in some analyses in this study or in other cases represented as a percentage of departure from recent observations.

\section{Modeled 5-cm Soil Moisture Record}

To place the current short period of observations in the context of the last decade, a machine learning algorithm was used to relate the observed 5 -cm soil moisture to precipitation measurements so that the soil moisture record could be extended back in time (where precipitation values are available but soil moisture records are not). For each of the 114 USCRN sites, the diagnostic soil moisture equation (Pan et al., 2003; Pan, 2012) was calibrated using the hourly, in situ observations and growing season climate data beginning at the station installation and concluding with the end of the 2012 growing season. Next, this simple soil moisture model was 
validated using data from the 2013 growing season (Coopersmith et al., 2015a). For the 91 sites for which a validation RMSE value below $0.05 \mathrm{~m}^{3} / \mathrm{m}^{3}$ was achieved, the soil moisture estimates were extended backward historically, using all growing season hours during which precipitation data were available. The validity of this approach was verified by Coopersmith et al. (2015a) and applied to comparisons with AMSR_E data by Coopersmith et al. (2015b).

The data used in the subsequent analysis involved the annual, average hourly soil moisture estimate during the months of June, July, and August for each USCRN site. For each hourly time stamp, when in situ estimates were available, they were used. When they were not, the calibrated model estimates were used in their place. This allowed the USCRN precipitation record (2005-2013 in most cases) to be deployed for further analysis.

\section{Analysis}

Monthly averages were created for each station's hourly volumetric soil moisture at every available soil depth. To illustrate the most pronounced signal of the 2012 drought and remove any possibility of signal contamination from subfreezing temperature periods, the summer months of June, July, and August (JJA) were chosen as the focus of all subsequent analyses. These data were then inspected to ensure that there were no faulty sensor values in the period of record. Summer seasonal averages of soil moisture were compared from 2011 to 2013 to investigate changes in conditions before, during, and after the 2012 drought. The first analysis performed for all stations in the network determined if there was a national signal for soil moisture during the 2012 drought. Stations were then grouped into their respective nine conterminous US climate regions (Karl and Koss, 1984) for further study (Fig. 1). Additional analysis of precipitation observations revealed the cumulative impacts of the drought during the same time period. Precipitation was analyzed on a hydrological year basis (October-September) to capture the influence on summer soil moisture.

\section{Results}

\section{Precipitation and Soil Moisture for 2012 Drought}

The USCRN historical (2005-2013) monthly precipitation averages were used as a basis to evaluate precipitation throughout the 2012 drought period both nationally and regionally for the United States. The 2012 year became progressively drier as the year continued (Fig. 2), with precipitation 16\% below the USCRN historical average. Monthly precipitation differences from the historical average provided some insight into how the 2012 drought evolved with time (Fig. 2). Accumulated precipitation differences reveal that the earliest drought signal (from precipitation data) appeared in late 2011, when a previous national surplus associated with the great floods in the Missouri River Basin was depleted by July of that year. Throughout 2012, the accumulated deficit intensified, particularly
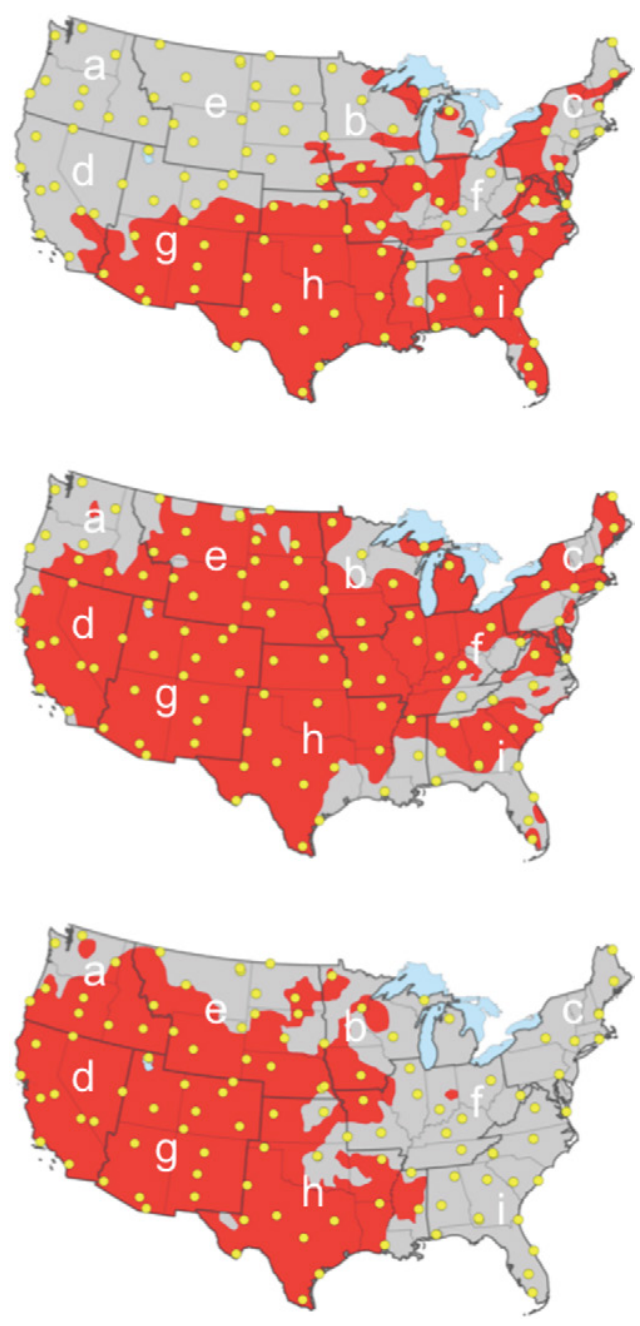

Fig. 1. The full extent of drought for the first week of August according to the US Drought Monitor for 2011 (top), 2012 (center), and 2013 (bottom) for nine climate regions: Northwest (a), Upper Midwest (b), Northeast (c), West (d), Northern Rockies and Plains (e), Ohio Valley (f), Southwest (g), South (h), and Southeast (i). The locations of the USCRN stations are indicated by yellow dots.

during the spring and summer months, before abating during the winter of 2012. Despite increased precipitation across the United States in 2013 (2.8\% less than the historical 2005-2013 average), the yearly precipitation value was not enough to recover fully from earlier 2012 deficits. This reflects the regional shift in drought from the southern United States in 2011 to the northern and central United States in 2012 and, eventually, to the West, where drought intensified in 2013.

Evaluation of the national soil moisture record at five depths was performed for JJA 2011, 2012, and 2013. Among all 3 yr, the JJA soil moisture was lowest in 2012 for all depths (Fig. 3). However, the rate at which soil moisture increased the following year was not consistent for all depths. The general pattern of recovery in soil moisture at 5,10 , and $20 \mathrm{~cm}$ was very similar to the change in precipitation during those $3 \mathrm{yr}$ (Fig. 4). However, little recovery of the national soil moisture conditions was seen at the 50-and 


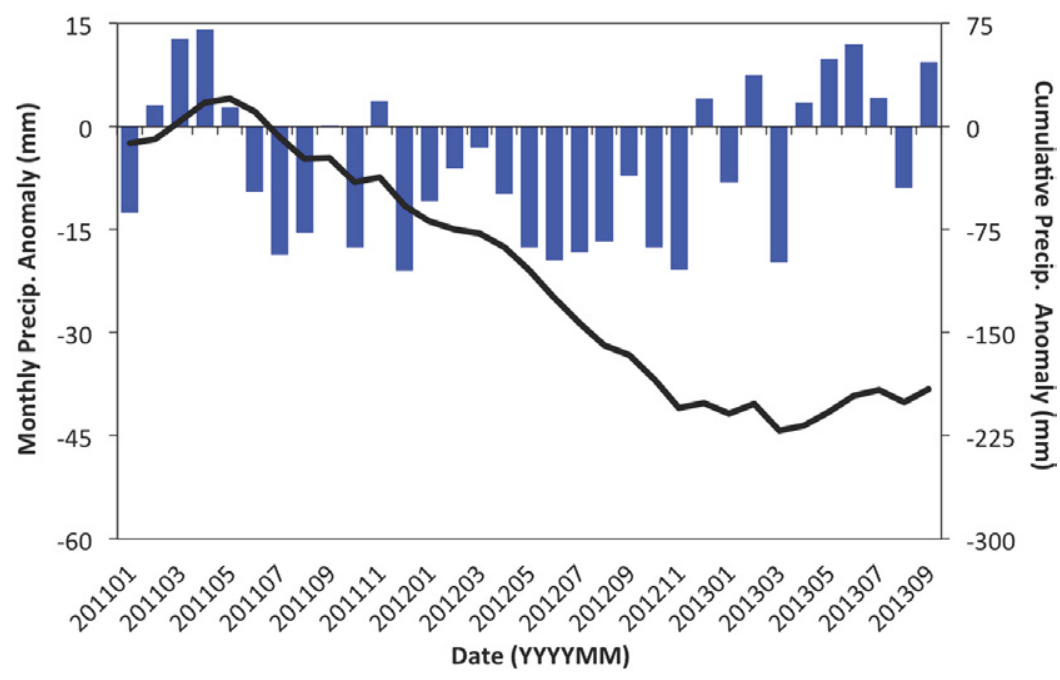

Fig. 2. The national scale of the change in precipitation during the 2012 drought. National USCRN calculated monthly precipitation (2011-2013) anomalies from the historical USCRN precipitation average (2005-2013) are indicated with blue bars. The black line represents the cumulative monthly USCRN precipitation anomaly from the historical average (2005-2013).

regions indicated on the map. The West and Northwest regions show only the patterns for 5,10 , and $20 \mathrm{~cm}$ because of the lack of deeper observations in those areas. The evolution of drought for the $3 \mathrm{yr}$ is especially evident in 2012 in the central and northern regions of the United States. The US South and Southeast, on the other hand, displayed the driest soil conditions in 2011, with the South partially recovering and the Southeast strongly recovering in 2013. Precipitation patterns are not always an indication of the patterns of soil moisture change. The changes in precipitation in the West and South were opposite of the response of the soil moisture patterns. The Northwest had a decreasing pattern in both precipitation and soil moisture from 2011 to 2012, but changes in the two variables from 2012 to 2013 did not follow the same patterns. The magnitude of change with precipitation and soil moisture was not always identical for different regions. The Northern Rockies and Plains had the greatest decrease in 2012, but soil moisture for that region did not reach the same percentage of change. Deeper soil depths, as seen at the

100-cm depths in 2013 (Fig. 3). Analysis of the change at each single depth between years indicates a consistent drying pattern during the 2012 period for all of the continental United States. Again, this pattern was seen at all depths, but the greatest recovery was in the 5-, 10-, and 20-cm depths (Fig. 4).

Regional soil moisture changes were not uniform across the continental United States (Fig. 5). Most prominent regional signals of the drought of 2012 were focused in the central and northern regions of the United States, as expected. Figure 5 displays the 2011 to 2013 regional percentage of average summer soil moisture at all recorded depths and precipitation for each of the nine climate

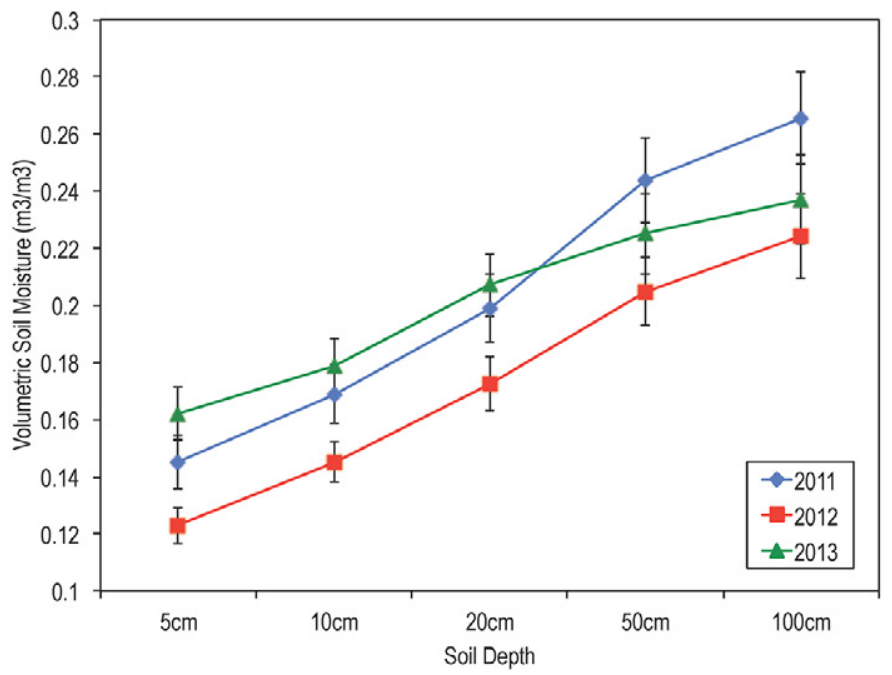

Fig. 3. The national soil moisture averages and standard errors calculated for 114 USCRN stations during the summer months (June, July, and August) of 2011 (blue), 2012 (red), and 2013 (green) for each measured soil depth $(5,10,20,50$, and $100 \mathrm{~cm})$. national level, produced more muted or completely unique patterns of change for different years.

\section{Modeled Soil Moisture}

Evaluation of the modeled soil moisture values for the percentage of change in soil moisture from 2005 to 2013 for the 5 -cm depth provided a historical context to the drought conditions experienced in 2012. Remaining consistent with the previous analysis, the results of the modeled soil moisture departures indicate that the 2012 totals for JJA were lower than for any other year in the study period (Fig. 6). The pattern remains consistent with the pattern seen in the actual soil observations, with a drying and rewetting before and after 2012, respectively. Because the USCRN was still installing additional stations in the early part of the historical record, the coverage across the United States was $<50 \%$ before 2004, ramping up to $100 \%$ in 2008 .

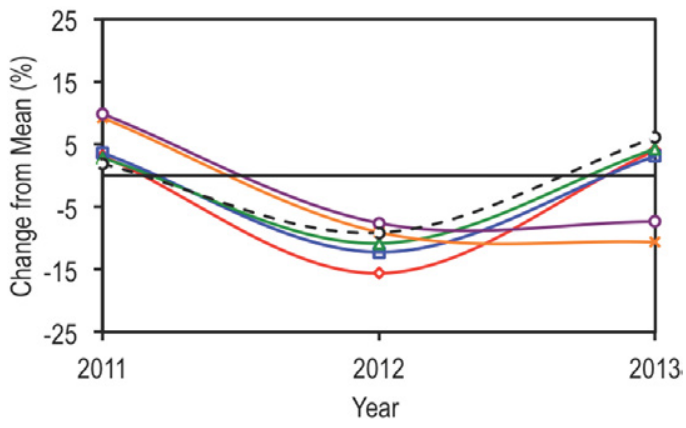

Fig. 4. The average change in summer (June, July, and August) soil moisture from the 3-yr average (2011-2013) for the 5-cm (red line, diamond), 10-cm (blue line, square), 20-cm (green line, triangle), $50-\mathrm{cm}$ (orange line, cross), and $100-\mathrm{cm}$ depths (purple line, circle). The dashed black line indicates the average change in total precipitation for each hydrological year from the 3-yr average (2011-2013). 


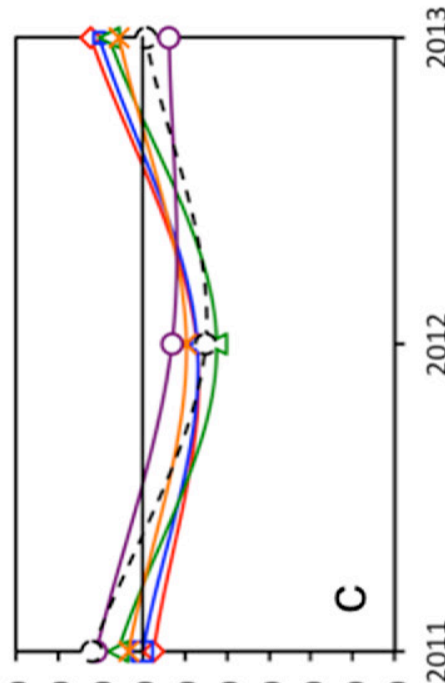

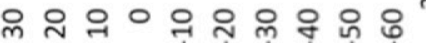

(\%) uеaw سоду ә8ిиечว

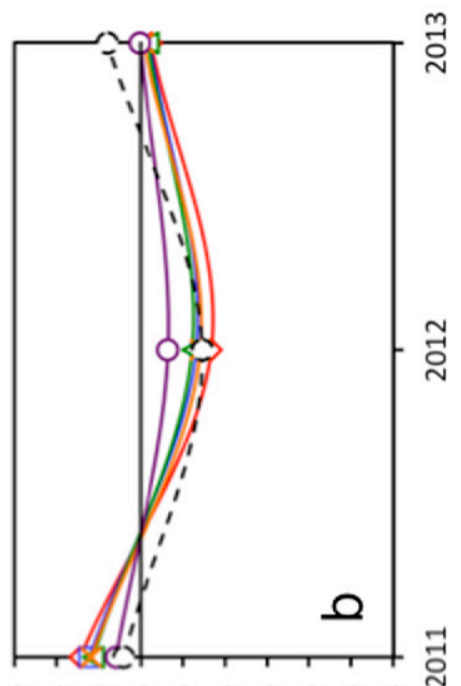

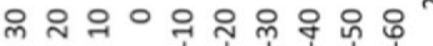

(\%) ueaw moдf ә8иечว

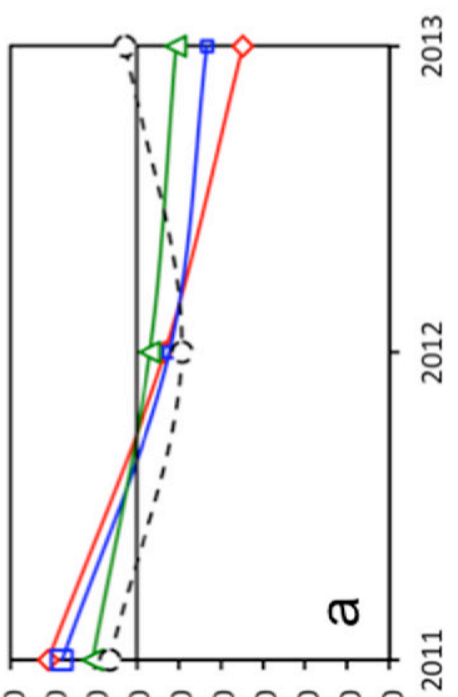

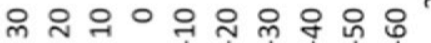

(\%) иeәW سод ә8ిиечว

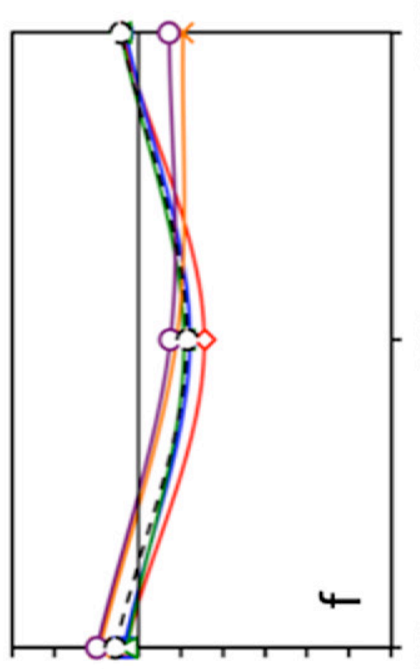

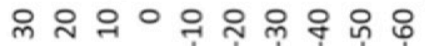

(\%) uеaw سоду әรиечว

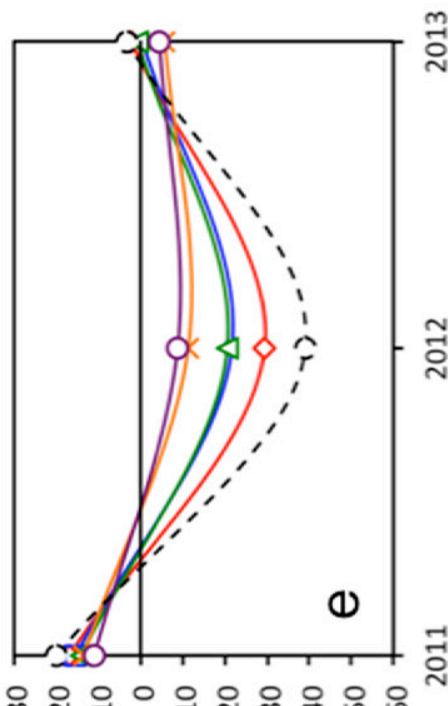

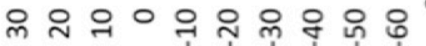

(\%) ueaw mody ә8ిиечว

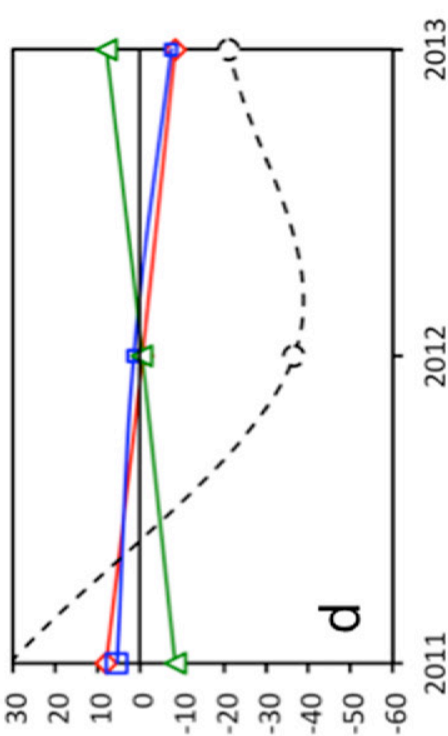

(\%) ueaw moдy ә8иечว

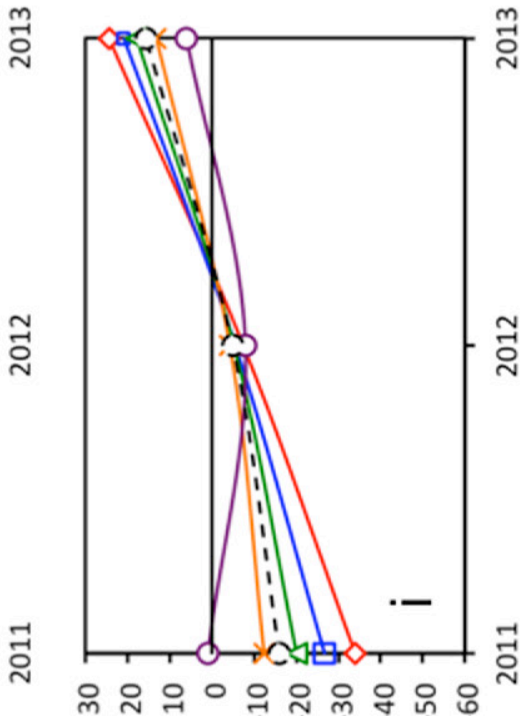

(\%) ueวw سody ә8ిиечว

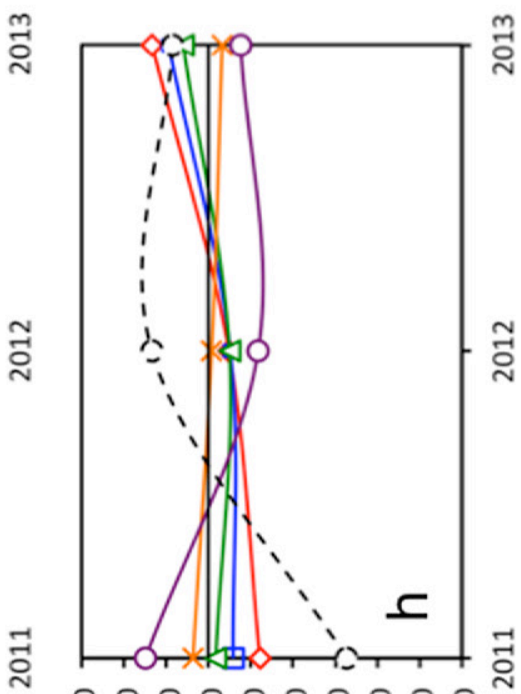

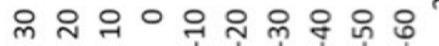

(\%) ueaw modf ә8ిиечว

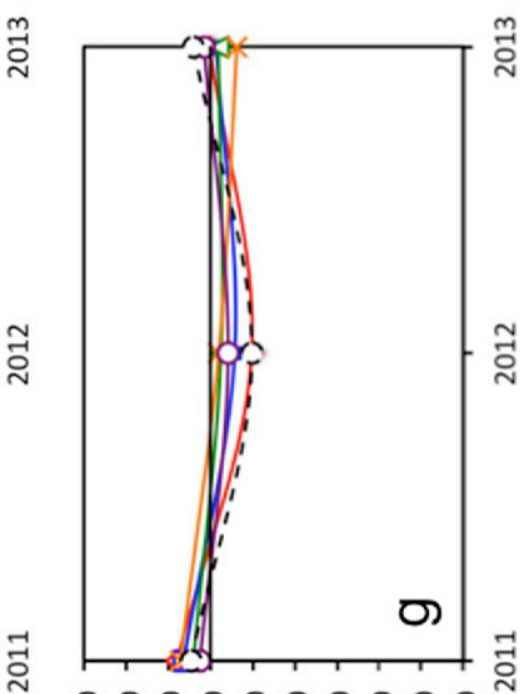

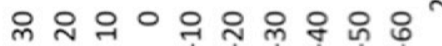

(\%) ueaw mody ә8яичu

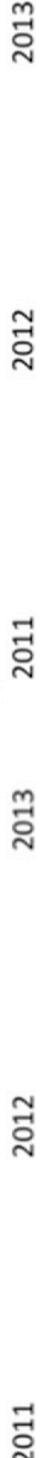

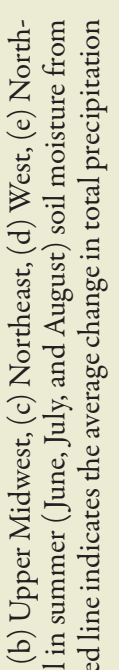

焉

过

घ

ख里它

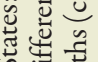

$\tilde{z}=$

行

要这

묻

है ส

:

幽

능

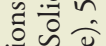

它

芩苛

ڤ

$\exists$ 누

दु

홍

ㅎํ으

छิ

氙苛言

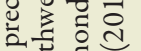

해

की

ह

․ำ

둥.

乙응형

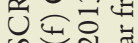

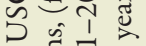

.

당

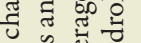

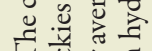

i

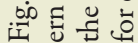




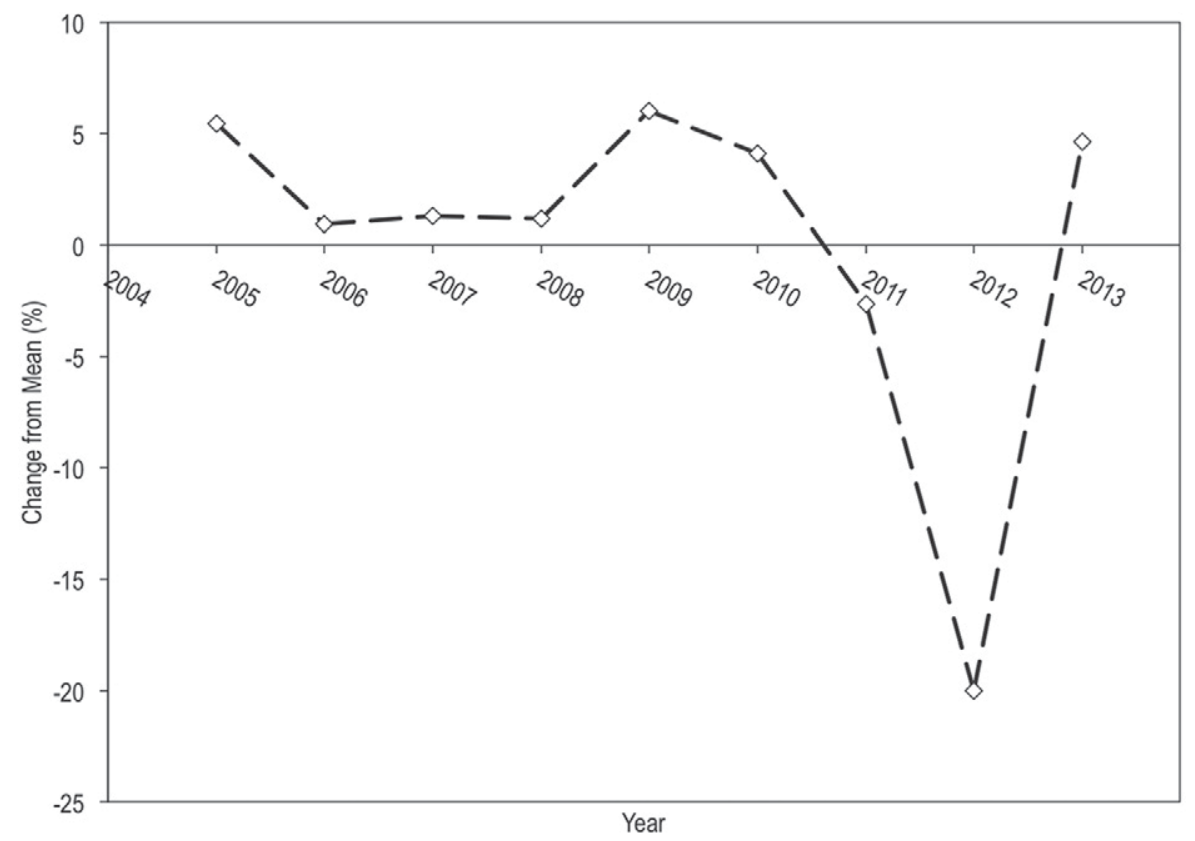

Fig. 6. Difference from the average in modeled $5-\mathrm{cm}$ soil moisture values for summer months (June, July, and August) for USCRN stations. Average soil moisture conditions were calculated from the entire period of record (2005-2013).

\section{Discussion and Summary}

The 2012 drought was associated with a dramatic reduction in soil moisture that was identified at both national and regional scales in the United States. The patterns of change in soil moisture were consistent with other drought monitoring metrics used to identify national changes in drought (Peterson et al., 2013; Hoerling et al., 2014). One of the most interesting results of this study was that the 50- and 100-cm national soil moisture levels did not recover fully from the 2012 drought and remained low in 2013. This lack of recovery in the deeper depths provides an interesting insight into soil moisture dynamics that can assist with understanding the severity of drought and the necessity for in situ networks for soil monitoring (Chew and Small, 2014). The lack of soil moisture recovery in deeper depths was probably the result of inadequate precipitation in 2013, which is evident in the lack of recovery in the cumulative precipitation (Fig. 2). While enough precipitation fell in 2013 to produce normal soil moisture levels in shallow soils, larger amounts of precipitation were required to recharge deep soils and underlying aquifers. Without adequate recovery at these deeper depths, there is an increased chance of relapse back to drought conditions with minimal drying of soils (Porporato et al., 2006). These results could also help improve land surface modeling efforts that may not be accurately representing the deeper soil moisture responses (Zhuo et al., 2015).

The fact that the regional patterns remained consistent with drought indices is especially promising for improving drought monitoring capabilities (Svoboda et al., 2002; Bell et al., 2013; Ochsner et al., 2013). While many regions experienced 2012 as the driest year in the 3-yr study period, the southern and western regions did not. Sparse data networks, such as the USCRN, have multiple limitations when it comes to large-scale analysis (Gruber et al., 2013). Because soil characteristics and changes in land cover can greatly impact the variability of soil measurements (Cosh et al., 2013), any large-scale analysis with a sparse network can be problematic. However, the results of this study were promising in that the analysis performed was able to capture the signals and responses at regional levels similar to the patterns previously identified by the US Drought Monitor map. In addition, the ability to characterize the change in deeper depths provides an opportunity for more precise evaluation of drought that is not captured by other drought indices that show more rapid recovery (Chew and Small, 2014).

The results also demonstrate that precipitation is not always a complete indicator of soil moisture conditions, which also respond to air temperature, relative humidity, and other factors. Multiple explanations can be given as to why the patterns in precipitation differences from average are not always consistent with soil moisture. For example, the western regions of the United States are generally relying on cold-season precipitation, and the summer soil moisture conditions can be very dry. Small changes in summer soil moisture in the West could represent a dramatic change expressed as a percentage from the average but may not reflect significant impacts on the system (Knapp et al., 2008).

As the soil moisture record length increases, the calculation of departures from the long-term averages will allow better identification of drought conditions and also act as a record of climate change (Bell et al., 2013). National in situ networks, like the USCRN, provide an ideal setup to understand soil moisture conditions and relate these changes to drought. To better interpret these results, a homogenous data record with similar sensor technology can reduce measurement uncertainty that comes from instrumentation biases. Because the USCRN uses the identical probe technology at each station, these biases are reduced and a more consistent measurement is provided (Palecki and Bell, 2013). However, the USCRN is still a relatively new network and limited data can reduce monitoring capabilities. Generating a modeled artificial soil moisture record is probably the best way to deal with the limitations of a short historical record (Coopersmith et al., 2015a, 2015b). Although we have generated the modeled soil moisture record for only the 5-cm depth, the utility of the extended record is apparent in our results by illustrating the severity of the change in soil moisture conditions for the 2012 period. Without an extended record, it is difficult to understand the current conditions in a historical context. 
Our results show that national soil moisture networks can provide insight into changes in the soil climate that may not be easily identifiable by other metrics. This was demonstrated by the finding that deeper depths did not recover from the 2012 drought and that certain regions experienced greater departures in soil moisture while changes in precipitation were not as large. Future insight into changes in soil climate may be gained as networks such as the USCRN acquires a longer period of record while also being well maintained (Diamond et al., 2013). As stations accumulate more data from the response of soil moisture dynamics to anomalies and normal conditions, our knowledge of soil climate will increase and improve drought monitoring capabilities.

\section{Acknowledgments}

This work was supported by NOAA through the Cooperative Institute for Climate and Satellites-North Carolina under Cooperative Agreement NA14NES432003. The USCRN is sup ported by the NOAA Climate Program Office. We especially thank M. Kruk and M. Brewer for their review comments and suggestions. We also thank T. Caldwell and three external reviewers for their editorial assistance. The views, opinions, and findings contained in this report are those of the authors and should not be construed as an official NOAA or US government position, policy, or decision. Data from this study can be accessed at the NOAA USCRN webpage (http://www.ncdc.noaa.gov/crn/).

\section{References}

Basara, J.B., J.N. Maybourn, C.M. Peirano, J.E. Tate, P.J. Brown, J.D. Hoey, and B.R. Smith. 2013. Drought and associated impacts in the Great Plains of the United States: A review. Int. J. Geosci. 4:72-81. doi:10.4236/ijg.2013.46A2009

Bell, J.E., M.A. Palecki, C.B. Baker, W.G. Collins, J.H. Lawrimore, R.D. Leeper, and H.J. Diamond. 2013. US Climate Reference Network soil moisture and temperature observations. J. Hydrometeorol. 14:977-988. doi:10.1175/JHM-D-12-0146.1

Blunden, J., and D.S. Arndt, editors. 2014. State of the climate in 2013. Bull. Am. Meteor. Soc. 95:S1-S279. doi:10.1 175/2014BAMSStateoftheClimate.1

Chew, C.C., and E.E. Small. 2014. Terrestrial water storage response to the 2012 drought estimated from GPS vertical position anomalies. Geophys. Res. Lett. 41:6145-6151. doi:10.1002/2014GL061206

Coopersmith, E.J., J.E. Bell, and M.H. Cosh. 2015a. Extending the soil moisture data record of the US Climate Reference Network (USCRN) and Soil Climate Analysis Network (SCAN). Adv. Water Resour. 79:80-90. doi:10.1016/j.advwatres.2015.02.006

Coopersmith, E.J., M.H. Cosh, R. Bindlish, and J.E. Bell. 2015b. Com paring AMSR-E soil moisture estimates to the extended record of the U.S. Climate Reference Network (USCRN). Adv. Water Resour. doi:10.1016/j.advwatres.2015.09.003

Cosh, M.H., T.J. Jackson, C. Smith, B. Toth, and A.A. Berg. 2013. Validating the BERMS in situ soil water content data record with a large scale temporary network. Vadose Zone J. 12(2). doi:10.2136/vzj2012.0151

Dai, A. 2013. Increasing drought under global warming in observations and models. Nat. Clim. Change 3:52-58. doi:10.1038/nclimate 1633

Diamond, H.J., T.R. Karl, M.A. Palecki, C.B. Baker, J.E. Bell, R.D. Leeper, and P.W. Thorne. 2013. US Climate Reference Network after one decade of operations: Status and assessment. Bull. Am. Meteorol. Soc. 94:485498. doi:10.1175/BAMS-D-12-00170.1

Fuchs, B.A., D.A. Wood, and D. Ebbeka. 2015. From too much to too little: How the central U.S. drought of 2012 evolved out of one of the most devastating floods on record in 2011 . Univ. of Nebraska, Lincoln.
http://www.drought.gov/media/pgfiles/CentralUSDroughtAssessment2012.pdf (accessed 13 Jan. 2015).

Gruber, A., W.A. Dorigo, S. Zwieback, A. Xaver, and W. Wagner. 2013. Characterizing coarse-scale representativeness of in situ soil moisture measurements from the International Soil Moisture Network. Vadose Zone J. 12(2). doi:10.2136/vzj2012.0170

Guttman, N.B. 1999. Accepting the standardized precipitation index: A calculation algorithm. J. Am. Water Resour. Assoc. 35:311-322. doi:10.1111/j.1752-1688.1999.tb03592.x

Hayes, M., M. Svoboda, N. Wall, and M. Widhalm. 2011. The Lincoln declaration on drought indices: Universal meteorological drought index recommended. Bull. Am. Meteorol. Soc. 92:485-488. doi:10.1175/2010BAMS3103.1

Hoerling, M., J. Eischeid, A. Kumar, R. Leung, A. Mariotti, K. Mo, and R. Seager. 2014. Causes and predictability of the 2012 Great Plains drought. Bull. Am. Meteorol. Soc. 95:269-282. doi:10.1 175/BAMS-D-13-00055.1

Hoerling, M., A. Kumar, R. Dole, J.W. Nielsen-Gammon, J. Eischeid, J. Perlwitz, et al. 2013. Anatomy of an extreme event. J. Clim. 26:281 1-2832. doi:10.1175/JCLI-D-12-00270.1

Karl, T.R., and W.J. Koss. 1984. Regional and national monthly, seasonal, and annual temperature weighted by area, 1895-1983. Hist. Climatol. Ser. 4-3. Natl. Clim. Data Ctr., Asheville, NC.

Knapp, A., C. Beier, D. Briske, A.T. Classen, Y. Luo, M. Reichstein, et al. 2008. Consequences of more extreme precipitation regimes for terrestrial ecosystems. BioScience 58:81 1-821. doi:10.1641/B580908

NOAA. 201 1. Global hazards: August 2011. Natl. Clim. Data Ctr., Asheville, NC. http://www.ncdc.noaa.gov/sotc/hazards/201108 (accessed 17 May 2015) .

Palecki, M.A., and J.E. Bell. 2013. US Climate Reference Network soil moisture observations with triple redundancy: Measurement variability. Vadose Zone J. 12(2). doi:10.2136/vzj2012.0158

Pan, F. 2012. Estimating daily surface soil moisture using a daily diagnostic soil moisture equation. J. Irrig. Drain. Eng. 138:625-631. doi:10.1061/ (ASCE)IR.1943-4774.0000450

Pan, F., C.D. Peters-Lidard, and M.J. Sale. 2003. An analytical method for predicting surface soil moisture from rainfall observations. Water Resour. Res. 39:1314. doi:10.1029/2003WR002142

Peterson, T.C., M.P. Hoerling, P.A. Stott, and S. Herring, editors. 2013. Explaining extreme events of 2012 from a climate perspective. Bull. Am. Meteor. Soc. 94:S1-S74. doi:10.1175/BAMS-D-13-00085.1

Porporato, A., G. Vico, and P.A. Fay. 2006. Superstatistics of hydro-climatic fluctuations and interannual ecosystem productivity. Geophys. Res. Lett. 33(15):L15402. doi:10.1029/2006GL026412

Ochsner, T.E., M.H. Cosh, R.H. Cuenca, W.A. Dorigo, C.S. Draper, Y. Hagimoto, and M. Zreda. 2013. State of the art in large-scale soil moisture monitoring. Soil Sci. Soc. Am. J. 77:1888-1919. doi:10.2136/sssaj2013.03.0093

Seyfried, M.S., L.E. Grant, E. Du, and K. Humes. 2005. Dielectric loss and calibration of the Hydra Probe soil water sensor. Vadose Zone J. 4:1070-1079. doi:10.2136/vzj2004.0148

Smith, A.B., and R.W. Katz. 2013. US billion-dollar weather and climate disasters: Data sources, trends, accuracy and biases. Nat. Hazards 67:387-410. doi:10.1007/s1 1069-013-0566-5

Svoboda, M., D. LeComte, M. Hayes, R. Heim, K. Gleason, J. Angel, et al. 2002. The Drought Monitor. Bull. Am. Meteorol. Soc. 83:1181-1190. doi:10.1175/1520-0477(2002)083<1181:TDM>2.3.CO;2

Vose, R.S., and M.J. Menne. 2004. A method to determine station density requirements for climate observing networks. J. Clim. 17:2961-2971. doi:10.1175/1520-0442(2004)017<2961:AMTDSD>2.0.CO;2

Zhuo, L., D. Han, Q. Dai, T. Islam, and P.K. Srivastava. 2015. Appraisal of NLDAS-2 multi-model simulated soil moistures for hydrological modelling. Water Resour. Manage. 29:3503-3517. doi:10.1007/s1 1269-015-1011-1 